\title{
Desafios da implementação da Política Nacional de Atenção Integral a Saúde do
}

\section{Homem em Mato Grosso}

\author{
Challenges of implementing the National Policy for Integral Attention to Man's Health in Mato \\ Grosso
}

Desafíos de implementar la Política Nacional de Atención Integral a la Salud del Hombre en Mato Grosso

Recebido: 04/01/2022 | Revisado: 09/01/2022 | Aceito: 14/01/2022 | Publicado: 18/01/2022

Lúcia Vitória da Silva Assunção de Souza ORCID: https://orcid.org/0000-0002-9291-6045 Universidade do Estado de Mato Grosso, Brasil E-mail: lucia.vitoria@unemat.br

Jeferson de Oliveira Silva ORCID: https://orcid.org/0000-0003-4834-4219 Prefeitura Municipal de Cáceres; Brasil E-mail: jefersonenfe@ hotmail.com

Poliana Roma Greve Nodari ORCID: https://orcid.org/0000-0002-6526-4758 Universidade do Estado de Mato Grosso; Brasil E-mail: polianaroma@unemat.br

Bianca Teshima de Alencar ORCID: https://orcid.org/0000-0001-6812-3494 Universidade do Estado de Mato Grosso; Brasil E-mail: bianca.teshima@unemat.br Raquel Borges Silva ORCID: https://orcid.org/0000-0002-0372-400X Universidade do Estado de Mato Grosso; Brasil E-mail: raquelborges@unemat.br

Mariana Lenina Menezes Aleixo ORCID: https://orcid.org/0000-0002-9363-2423 Universidade do Estado de Mato Grosso; Brasil E-mail: mariana.aleixo@unemat.br

\begin{abstract}
Resumo
Objetivo: identificar os desafios da implementação da Política Nacional de Atenção Integral a Saúde do Homem, em Mato Grosso. Método: revisão integrativa da literatura, de publicações do período de 2012 a dezembro de 2020, nas bases de dados CAPES, MEDLINE, LILACS, SciELO e Google Acadêmico. Resultados: foram selecionados 17 artigos para confecção deste trabalho. Os desafios identificados na implementação da política estão relacionados à: entraves na consolidação da política, aspectos culturais gênero/masculinidade, educação continuada e capacitação para os profissionais de saúde, o horário de funcionamento das unidades e poucas ações educativas direcionadas para essa população. Conclusão: a capacitação permanente dos profissionais de saúde da Atenção Básica visando a prática de atividades específicas de acordo com as diretrizes da política, a organização e realização de atividades estratégicas, de fácil acesso ao homem, além da adequação quanto o horário de funcionamento nas unidades, torna-se fundamental para a sensibilização e adesão dos mesmos.
\end{abstract}

Palavras-chave: Saúde do homem; Políticas públicas; Enfermagem; Atenção básica.

\begin{abstract}
Objective: to identify the challenges of implementing the National Policy for Comprehensive Attention to Men's Health, in Mato Grosso. Methodology: integrative literature review of publications from 2012 to December 2020, in CAPES, MEDLINE, LILACS, SciELO and Academic Google databases. Results: 17 articles were selected for this work. The challenges identified in the implementation of the policy are related to: obstacles in the consolidation of the policy, cultural aspects of gender/masculinity, continuing education and training for health professionals, the hours of operation of the units and few educational actions aimed at this population. Conclusion: the permanent training of health professionals in Primary Care aiming at the practice of specific activities in accordance with the policy guidelines, the organization and performance of strategic activities, easily accessible to men, in addition to the adequacy of the hours of operation in the units, becomes fundamental for their awareness and adherence.
\end{abstract}

Keywords: Men's health; Public policy; Nursing; Basic attention. 


\begin{abstract}
Resumen
Objetivo: identificar los desafíos de la implementación de la Política Nacional de Atención Integral a la Salud del Hombre, en Mato Grosso. Metodología: revisión integradora de la literatura de las publicaciones de 2012 a diciembre de 2020, en las bases de datos CAPES, MEDLINE, LILACS, SciELO y Academic Google. Resultados: se seleccionaron 17 artículos para este trabajo. Los desafíos identificados en la implementación de la política están relacionados con: obstáculos en la consolidación de la política, aspectos culturales de género / masculinidad, educación y formación continua para los profesionales de la salud, los horarios de funcionamiento de las unidades y pocas acciones educativas dirigidas a esta población. Conclusión: la formación permanente de los profesionales sanitarios en Atención Primaria con miras a la práctica de actividades específicas de acuerdo con los lineamientos de la política, la organización y realización de actividades estratégicas, de fácil acceso para los hombres, además de la adecuación del horario de atención en unidades, se vuelve fundamental para su conciencia y adherencia.
\end{abstract}

Palabras clave: Salud de los hombres; Políticas públicas; Enfermería; Atención básica.

\title{
1. Introdução
}

A população masculina, geralmente é atingida por mais doenças crônicas do que a feminina e morrem mais do que elas. A longevidade feminina é, em média, sete anos a mais quando comparada à masculina (Lopes, 2015). Deste modo, a qualidade de vida do homem inquieta as autoridades em saúde devido as elevadas taxas de mortalidade, a baixa procura e o escasso acesso do público masculino nos serviços de atenção primária (Garcia et al., 2013).

Nesse âmbito, entendeu-se a necessidade da adoção de medidas que visassem o aumento da expectativa de vida e redução dos índices de morbidade e mortalidade masculina e dessa forma, institucionalizou-se a Política Nacional de Atenção Integral a Saúde do Homem (PNAISH) pela portaria ${ }^{\circ}{ }^{1944}$, de 2009, essa política foi planejada com o objetivo de promover a melhoria das condições de saúde da população masculina do Brasil, prioritariamente na faixa etária de 20 a 59 anos (Brasil, 2009).

As ações em saúde implementadas a partir da política desenvolvem-se em cinco eixos temáticos: Acesso e Acolhimento, Saúde Sexual e reprodutiva, Paternidade e Cuidado, Doenças prevalentes na população masculina e Prevenção de violências e acidentes. Estes eixos foram inseridos com a intenção de reorganizar, desenvolver e fortalecer as ações de saúde, além de sensibilizar gestores, profissionais de saúde e a população em geral sobre uma proposta inclusiva e envolvimento ativo da população masculina na assistência básica (Ramos, 2019).

As ações práticas de saúde adotadas na PNAISH são definidas pelas três esferas de governo, respeitando a autonomia de estados e municípios, entretanto, as medidas definidas pelos gestores têm correspondido às necessidades de saúde e realidade epidemiológica de Estados e municípios (Brasil, 2009; Da Rocha et al., 2019).

A dificuldade na implementação da PNAISH, está associada ao próprio homem, pois a construção social da masculinidade se processa desde o início da vida através das diferenças na socialização de meninos e meninas, fazendo com que os meninos não sejam motivo de preocupações por parte dos adultos, dessa forma, na idade adulta têm sua qualidade de vida afetada, permitindo se expor a situações de riscos e resistindo cuidar de sua saúde (Duarte et al., 2012). E, a partir do modelo de gênero firmado socialmente, adotou-se normas e padrões de comportamento a serem seguidas pelos homens em suas interações sociais, havendo consequentemente redução da busca por assistência à saúde (Ferreira, 2013).

Outra dificuldade na implementação da PNAISH, está relacionada ao despreparo dos profissionais de saúde, uma vez que, as qualificações dos mesmos são ineficientes devido à falta de incentivo por parte de gestores para treinamentos e capacitações continuada (Leal et al., 2012).

Devido à adesão dos homens na procura pelos serviços de saúde da atenção primária ainda ser escassa, há uma maior demanda nos serviços ambulatoriais e especializados, limitando o perfil dos pacientes aos idosos com patologias crônicas ou infecções contagiosas nos serviços de atenção primária (Adamy et al., 2015; Oliveira et al., 2015).

O Ministério da Saúde (MS) a fim de organizar de maneira regular os serviços preventivos e educação em saúde, considerando que a maior procura por atendimento especializado, além de agravar o estado de saúde do homem, gera maiores 
gastos ao SUS, reconheceu a necessidade de fortalecer e qualificar a atenção primária de forma a garantir a promoção da saúde e prevenção de agravos evitáveis, através de estratégias que visassem informar e sensibilizar os homens quanto ao autocuidado, melhorar o atendimento de forma resolutiva dos serviços prestados e o aperfeiçoamento de educação permanente dos trabalhadores do SUS (Brasil, 2009).

No enfoque da saúde do homem este trabalho justifica-se discutir sobre a implementação da PNAISH no acompanhamento integral do público masculino, uma vez que o próprio homem não tem interesse em cuidar da própria saúde, tornando o enfermeiro da Atenção Básica um grande aliado nesse processo complexo e contínuo de diminuir as dificuldades desse atendimento. Face ao exposto, o estudo busca responder ao seguinte problema: Quais os desafios da implementação da Política Nacional de Atenção Integral a Saúde do Homem em Mato Grosso, relacionando com a sua evolução no período de 2012 a dezembro de 2020 ?

Este trabalho tem como objetivo identificar os desafios da implementação da Política Nacional de Atenção Integral a Saúde do Homem, em Mato Grosso.

\section{Metodologia}

Este estudo caracteriza-se como uma revisão da literatura de abordagem integrativa. Segundo De Sousa (2017), as pesquisas de abordagem integrativa têm como finalidade sintetizar resultados obtidos em pesquisas sobre um tema ou questão, de maneira sistemática, ordenada e abrangente. É denominada integrativa porque fornece informações mais amplas sobre um assunto/problema, constituindo, assim, um corpo de conhecimento.

Para elaboração dessa revisão, foram executadas seis etapas integrativas com o objetivo de padronizar o sistema de busca: (1) delimitação do tema; (2) definição dos critérios de inclusão e exclusão; (3) pesquisa dos trabalhos por meio dos descritores; (4) busca nas bases de dados; (5) leitura analítica dos trabalhos e (6) apresentação e discussão dos resultados.

A questão norteadora desse estudo foi elaborada por meio da estratégia PICO, que representa o acrônimo População, Intervenção, Comparação da intervenção (se aplicável) e Outcomes (Resultados), essa estratégia é capaz de ampliar a recuperação de evidências nas bases de dados, podendo ser aplicada na construção da questão norteadora de pesquisas em diversas áreas. Diante do exposto, a questão norteadora desta revisão foi: Quais os desafios da implementação da Política Nacional de Atenção Integral a Saúde do Homem em Mato Grosso, relacionando com a sua evolução no período de 2012 a dezembro de 2020.

Com a intenção de complementar os dados disponíveis, especificou-se o nível de evidência de cada artigo científico conforme seu delineamento metodológico, a saber: Nível 1: evidências decorrentes da meta-análise de múltiplos estudos clínicos controlados e randomizados; Nível 2: evidências resultantes de estudos individuais com delineamento experimental; Nível 3: evidências de estudos quase-experimentais; Nível 4: evidências de estudos descritivos (não-experimentais) ou com abordagem qualitativa; Nível 5: evidências originárias de relatos de caso ou de experiência; Nível 6: evidências baseadas em opiniões de especialistas (Stetler et al., 2006).

As buscas foram realizadas nas bases de dados eletrônicos on-line, Portal de periódicos da CAPES, MEDLINE (Medical Literature Analysis and Retrieval System Online), LILACS (Literatura Latino-Americana e do Caribe em Ciências da Saúde), SciELO (Scientific Electronic Library Online) e Google Acadêmico.

Os descritores utilizados para a pesquisa dos trabalhos foram: Saúde do homem, Políticas Públicas, Enfermagem, Atenção Básica. Foi aplicado o operador booleano "AND”. Foram usados os quatros descritores como termo de busca juntos e em outras pesquisas intercalados, como por exemplo, "Saúde do Homem" AND "Políticas Públicas", "Saúde do Homem" AND "Enfermagem" AND "Atenção Básica".

Como critérios de inclusão foram selecionados trabalhos que estavam disponíveis na íntegra, publicados entre os anos 
2012 a dezembro 2020 e no idioma português, que abordavam o tema proposto. Quanto ao critério de exclusão foram retirados trabalhos publicados em sites, jornais, livros e resenhas.

Posteriormente a pesquisa bibliográfica, foi realizada triagem dos trabalhos na íntegra, através de uma leitura analítica dos títulos e resumos, em organização das ideias de acordo com a questão norteadora e os critérios de inclusão. Todos os trabalhos escolhidos nesta etapa obtiveram ordem de importância conforme os critérios pré-determinados, na sequência foi realizado a sintetização dos resultados da pesquisa. O processo de seleção de artigos está apresentado na Figura 1, a seguir:

Figura 1. Fluxograma do processo de seleção de artigos da revisão integrativa.

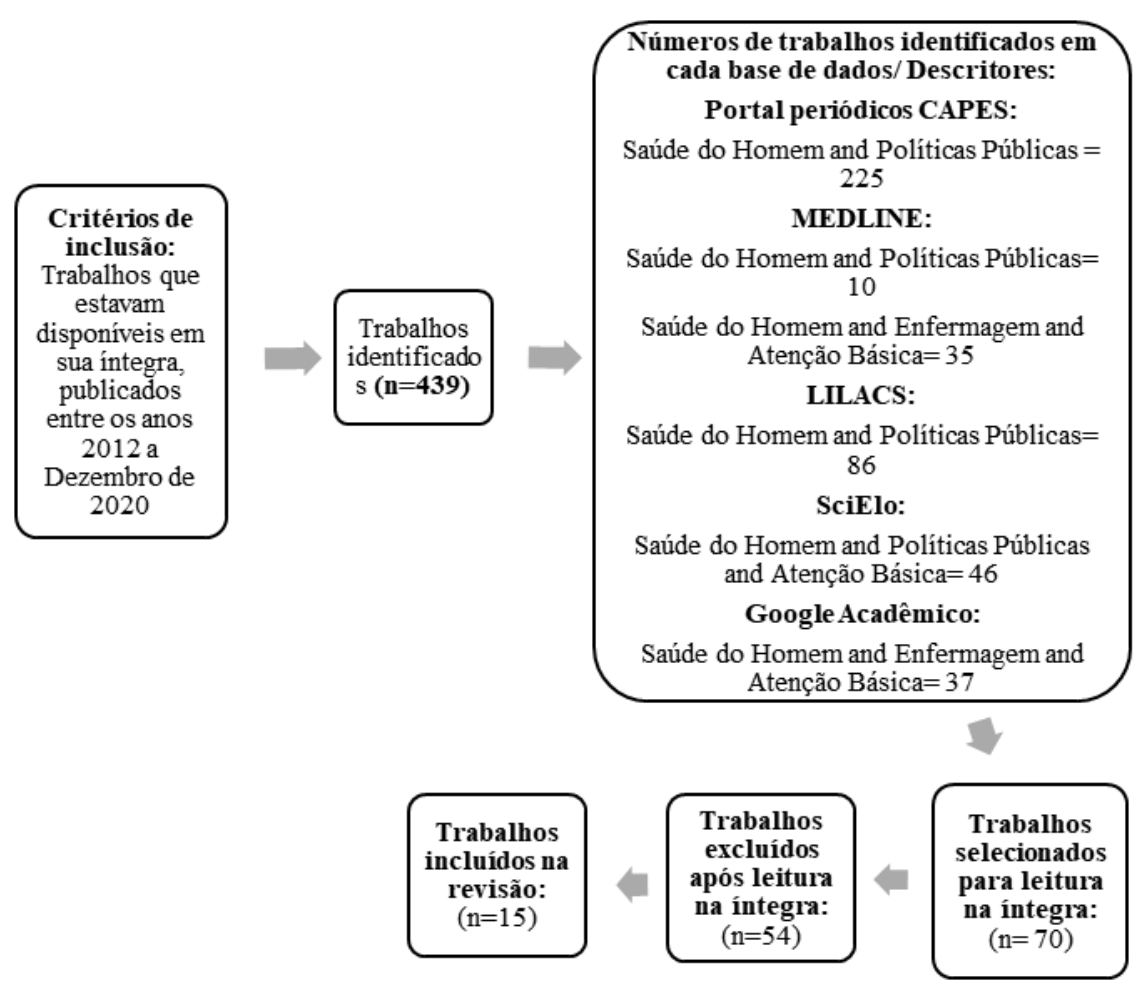

Fonte: Autoria própria.

A pesquisa resultou em 439 artigos de interesse na primeira etapa, foram excluídos 423 artigos na segunda etapa por não apresentarem os critérios de inclusão descritos na metodologia. Desconsiderando os artigos duplicados nas bases de dados pesquisadas, um total de 17 artigos foram analisados integralmente para confecção deste trabalho, dois destes em fase de publicação, e por isso não disponibilizado nas bases de dados.

Posteriormente, os artigos encontrados foram divididos em três categorias para discussão de resultados, sendo: 1 . Dificuldade para implantação e implementação; 2. O homem e os serviços de saúde; 3. Atuação dos profissionais de saúde na implementação da política de saúde do homem.

\section{Resultados e Discussão}

Os temas abordados nos artigos selecionados dizem respeito a questões como: gênero, adoecimento, autocuidado, inserção do homem nas políticas públicas, barreiras de acesso da população masculina nos serviços de saúde e variaram com a visão de gestores, profissionais de saúde e a visão do usuário.

Os resultados evidenciaram que os desafios para implementação da Política Nacional de Atenção Integral à Saúde do Homem, em Mato Grosso, apresentam situação semelhante à encontrada em outras localidades, onde estudos similares foram conduzidos. 
Dessa forma, pode-se dizer que desafios da implementação da política estão relacionados à: entraves na consolidação da política, aspectos culturais gênero/masculinidade, estrutura organizacional e física, educação continuada e capacitação para os profissionais de saúde, o horário de funcionamento das unidades e poucas ações educativas direcionadas para essa população.

No que tange ao delineamento metodológico, houve predomínio de estudos de natureza qualitativa. Em maior parte, os artigos estão no nível cinco de evidência, ou seja, evidências resultantes de estudos originários de relatos de caso ou experiência, indicando baixo nível de evidência científica. No Quadro 1, está apresentada a descrição dos artigos selecionados, com autores, ano, objetivos, método, nível de evidência e principais resultados.

Quadro 1. Descrição dos artigos selecionados na revisão para análise de dados e discussão de resultados, em ordem cronológica.

\begin{tabular}{|c|c|c|c|c|}
\hline Autores / Ano & Objetivos & Metodologia & Evidência & Principais Resultados \\
\hline $\begin{array}{l}\text { Duarte et al. } \\
2012\end{array}$ & $\begin{array}{l}\text { Refletir sobre a operacionalização } \\
\text { da Política Saúde do Homem no } \\
\text { cotidiano do trabalho na atenção } \\
\text { primária à saúde }\end{array}$ & $\begin{array}{l}\text { Revisão de } \\
\text { literatura }\end{array}$ & $\begin{array}{l}\text { Qualitativo/ } \\
\text { Nível } 5\end{array}$ & $\begin{array}{c}\text { Muitos são os desafios para a efetivação da PSH } \\
\text { e sua implementação estão relacionadas aos } \\
\text { aspectos socioculturais e organização das } \\
\text { unidades de saúde. }\end{array}$ \\
\hline Leal et al. 2012 & $\begin{array}{c}\text { Compreender como a Política } \\
\text { Nacional de Atenção Integral à } \\
\text { Saúde dos Homens (PNAISH) } \\
\text { chega aos serviços da Atenção } \\
\text { Básica do Sistema Único de Saúde, } \\
\text { a partir do ponto de vista dos seus } \\
\text { profissionais }\end{array}$ & Estudo etnográfico & $\begin{array}{l}\text { Qualitativo/ } \\
\text { Nível } 5\end{array}$ & $\begin{array}{l}\text { Observou-se desconhecimento ineficiente dos } \\
\text { agentes implementadores sobre a } \\
\text { PNAISH, a rede local de atenção à saúde do } \\
\text { homem, as técnicas para atender às } \\
\text { especificidades dos homens e o conceito de } \\
\text { gênero. A implementação esbarrou na ausência } \\
\text { de condições institucionais, como uma estrutura } \\
\text { organizacional, uma } \\
\text { rede consolidada de atenção e recursos em geral, } \\
\text { especialmente humanos. }\end{array}$ \\
\hline $\begin{array}{l}\text { Ferreira, M. C. } \\
2013\end{array}$ & $\begin{array}{c}\text { Analisar as barreiras existentes que } \\
\text { dificultam a } \\
\text { consolidação da Política de } \\
\text { Atenção Integral à Saúde do } \\
\text { Homem no Brasil. }\end{array}$ & $\begin{array}{c}\text { Revisão } \\
\text { Bibliográfica }\end{array}$ & Qualitativo/ Nível 4 & $\begin{array}{l}\text { As questões de gênero/masculinidade impedem } \\
\text { que os homens acessem os serviços de saúde por } \\
\text { conta da concepção de invulnerabilidade, } \\
\text { vergonha e medo de descobrir uma doença } \\
\text { incapacitante. As outras barreiras estão } \\
\text { associadas ao horário de funcionamento das } \\
\text { unidades básicas, falta de especialista, número de } \\
\text { profissionais insuficientes e poucas ações } \\
\text { educativas direcionadas para essa população. }\end{array}$ \\
\hline $\begin{array}{l}\text { Garcia et al. } \\
2013\end{array}$ & $\begin{array}{c}\text { Buscar entender e/ou buscar } \\
\text { justificativas para a baixa procura } \\
\text { dos homens as UBS }\end{array}$ & $\begin{array}{c}\text { Revisão integrativa } \\
\text { de literatura }\end{array}$ & $\begin{array}{l}\text { Qualitativo/ } \\
\text { Nível } 4\end{array}$ & $\begin{array}{l}\text { É pequena a presença de homens nas UBS, e que } \\
\text { essa pequena parcela não se encontra satisfeita } \\
\text { com a situação, pois poderia haver um } \\
\text { melhoramento no ambiente, e contratação de } \\
\text { profissionais do sexo masculino, especializados } \\
\text { na saúde do homem, e mais ações voltadas ao } \\
\text { público masculino, o que acontece pouco. Um } \\
\text { aumento na demanda de consultas e exames, e } \\
\text { um horário diferenciado, para que os clientes do } \\
\text { sexo masculino não precisassem faltar o serviço } \\
\text { para ir a uma consulta. }\end{array}$ \\
\hline $\begin{array}{l}\text { Araújo et al. } \\
2014\end{array}$ & $\begin{array}{c}\text { Identificar a opinião de } \\
\text { profissionais de saúde para a } \\
\text { efetivação da Política Nacional de } \\
\text { Atenção Integral à Saúde do } \\
\text { Homem. }\end{array}$ & $\begin{array}{c}\text { Pesquisa } \\
\text { exploratória/descrit } \\
\text { iva com abordagem } \\
\text { qualitativa }\end{array}$ & $\begin{array}{l}\text { Qualitativo/ } \\
\text { Nível } 5\end{array}$ & $\begin{array}{l}\text { Os sujeitos consideram que a política é relevante } \\
\text { para trabalhar ações para o homem. No entanto, } \\
\text { o seu processo formativo foi centrado na atenção } \\
\text { às doenças, fragmentado e excessivamente } \\
\text { biomédico, problematizando o desenvolvimento } \\
\text { de práticas de promoção da saúde. Outra } \\
\text { dificuldade é a ausência de ações coletivas e a } \\
\text { falta de capacitação para trabalhar com a } \\
\text { população masculina. }\end{array}$ \\
\hline $\begin{array}{c}\text { Mozer e Corrêa } \\
2014\end{array}$ & $\begin{array}{c}\text { Analisar o processo de } \\
\text { implementação da Política } \\
\text { Nacional de Atenção Integral à } \\
\text { Saúde do Homem (PNAISH) em } \\
\text { Cuiabá, tomando por referência } \\
\text { gênero, conforme proposta } \\
\text { Ministerial. }\end{array}$ & $\begin{array}{l}\text { Pesquisa de } \\
\text { abordagem } \\
\text { qualitativa }\end{array}$ & $\begin{array}{l}\text { Qualitativo/ } \\
\text { Nível } 5\end{array}$ & $\begin{array}{l}\text { As ações de saúde propostas situam-se no campo } \\
\text { das práticas voltadas para o atendimento às } \\
\text { necessidades em saúde relativas aos aspectos } \\
\text { biomédicos, estas ações, de maneira geral, não } \\
\text { favoreceram a necessária mudança de } \\
\text { comportamentos } \\
\text { vulneráveis relacionados ao gênero, não } \\
\text { ocorrendo a efetiva implementação da PNAISH. }\end{array}$ \\
\hline $\begin{array}{c}\text { Teixeira et al. } \\
2014\end{array}$ & $\begin{array}{l}\text { Distinguir analiticamente, a partir } \\
\text { de uma perspectiva de gênero, } \\
\text { necessidades de saúde relativas ao }\end{array}$ & $\begin{array}{l}\text { Estudo } \\
\text { exploratório- } \\
\text { descritivo, } \\
\end{array}$ & $\begin{array}{l}\text { Qualitativo/ } \\
\text { Nível } 5\end{array}$ & $\begin{array}{l}\text { Estes manifestaram, sobretudo, a necessidade de } \\
\text { provimento de segurança financeira à família, } \\
\text { destacando também a necessidade de bem-estar }\end{array}$ \\
\hline
\end{tabular}


Research, Society and Development, v. 11, n. 2, e5311225354, 2022

(CC BY 4.0) | ISSN 2525-3409 | DOI: http://dx.doi.org/10.33448/rsd-v11i2.25354

\begin{tabular}{|c|c|c|c|c|}
\hline & $\begin{array}{l}\text { evento de pós-nascimento de um } \\
\text { filho, experimentadas, expressas } \\
\text { e/ou negadas pelos homens. }\end{array}$ & qualitativo & & $\begin{array}{l}\text { do filho, acessando o retorno afetivo que a } \\
\text { experiência traz. Não se reconheciam com } \\
\text { necessidades de saúde no pós-nascimento. }\end{array}$ \\
\hline $\begin{array}{l}\text { Adamy et al. } \\
2015\end{array}$ & $\begin{array}{l}\text { Conhecer como está a implantação } \\
\text { da Política Nacional de Atenção } \\
\text { Integral à Saúde do Homem } \\
\text { (PNAISH) sob a ótica dos gestores } \\
\text { do Sistema Único de Saúde em } 15 \\
\text { municípios do oeste de Santa } \\
\text { Catarina, no sul do Brasil. }\end{array}$ & $\begin{array}{c}\text { Pesquisa } \\
\text { exploratória/descrit } \\
\text { iva com abordagem } \\
\text { qualitativa }\end{array}$ & $\begin{array}{l}\text { Qualitativo/ } \\
\text { Nível } 5\end{array}$ & $\begin{array}{l}\text { Apontam fragilidades no discurso sobre o } \\
\text { conhecimento da Política. As ações realizadas } \\
\text { nos municípios estão focadas na detecção do } \\
\text { câncer de próstata, aumento do número de } \\
\text { consulta médicas especializadas e no controle de } \\
\text { algumas doenças crônicas. Evidencia-se a } \\
\text { necessidade de capacitar os gestores e de } \\
\text { diversos investimentos para implantação e } \\
\text { consolidação da PNAISH na realidade } \\
\text { pesquisada. }\end{array}$ \\
\hline Lopes, C.S. 2015 & $\begin{array}{l}\text { Caracterizar/investigar ações de } \\
\text { promoção de saúde do homem, } \\
\text { quais são os trabalhos } \\
\text { desenvolvidos pelos Enfermeiros e } \\
\text { descrever o conhecimento, à luz da } \\
\text { Política Nacional de Atenção } \\
\text { Integral à Saúde do Homem - } \\
\text { PNAISH. }\end{array}$ & Estudo qualitativo & $\begin{array}{l}\text { Qualitativo/ } \\
\text { Nível } 5\end{array}$ & $\begin{array}{l}\text { Verificou-se que os profissionais conhecem a } \\
\text { PNAISH, e a sua aplicação é pouca efetivada nos } \\
\text { ESFs, } 22 \% \text { desenvolve ações anuais com } \\
\text { informativos preventivos e } 56 \% \text { não realizam } \\
\text { ações devido à falta de qualificação por parte dos } \\
\text { profissionais e apoio financeiro, por parte dos } \\
\text { gestores municipais. }\end{array}$ \\
\hline $\begin{array}{c}\text { Silva e } \\
\text { Magalhães } 2015\end{array}$ & $\begin{array}{l}\text { Identificar características sociais, } \\
\text { econômicas, socioculturais, hábitos } \\
\text { de vida e, principalmente, } \\
\text { elementos que dificultem no } \\
\text { momento da procura por } \\
\text { assistência de saúde pelo público } \\
\text { masculino entrevistado. }\end{array}$ & $\begin{array}{l}\text { Pesquisa descritiva, } \\
\text { qualitativa e } \\
\text { quantitativa }\end{array}$ & $\begin{array}{l}\text { Qualitativo e } \\
\text { quantitativo/ } \\
\text { Nível } 5\end{array}$ & $\begin{array}{l}\text { Percebeu-se que se trata de indivíduos situados } \\
\text { em faixa etária mais elevada, em sua maioria, de } \\
\text { baixa renda familiar e não portadores de HA e } \\
\text { DM, isentos de hábitos de vida prejudiciais como } \\
\text { tabagismo e etilismo. As dificuldades basearam- } \\
\text { se em falta de insumos, de profissionais e tempo } \\
\text { de atendimento demorado. }\end{array}$ \\
\hline $\begin{array}{c}\text { Oliveira et al. } \\
2015\end{array}$ & $\begin{array}{c}\text { Analisar o perfil sócio } \\
\text { demográfico, de morbidade e } \\
\text { frequência da busca por um serviço } \\
\text { de saúde de homens adultos } \\
\text { cadastrado em um setor do } \\
\text { Programa } \\
\text { Médico de Família do município de } \\
\text { Niterói (RJ). }\end{array}$ & Estudo transversal & $\begin{array}{l}\text { Qualitativo/ } \\
\text { Nível } 4\end{array}$ & $\begin{array}{l}\text { Dos } 323 \text { homens cadastrados, } 56 \% \text { buscaram } \\
\text { atendimento. O principal motivo que demandou } \\
\text { o primeiro atendimento foi consulta de rotina. } \\
\text { Observou-se que } 43 \text { homens apresentaram } \\
\text { excesso de peso, } 26 \text { eram obesos e que } 44 \\
\text { tiveram a pressão arterial alterada. O perfil dos } \\
\text { homens que buscaram e daqueles não buscaram } \\
\text { atendimento apresentou diferenças } \\
\text { estatisticamente significativas para: idade, } \\
\text { escolaridade, seguro social e referência à } \\
\text { morbidade no momento do cadastro. Os homens } \\
\text { mais velhos, com seguro social, que relataram } \\
\text { alguma morbidade buscaram mais o serviço de } \\
\text { saúde. }\end{array}$ \\
\hline $\begin{array}{l}\text { Da Rocha et al. } \\
2016\end{array}$ & $\begin{array}{c}\text { Identificar os principais desafios } \\
\text { para implementação da Política } \\
\text { Nacional de Atenção Integral à da } \\
\text { Saúde do Homem }\end{array}$ & $\begin{array}{l}\text { Revisão da } \\
\text { literatura com } \\
\text { abordagem } \\
\text { qualitativa }\end{array}$ & $\begin{array}{l}\text { Qualitativo/ } \\
\text { Nível } 4\end{array}$ & $\begin{array}{l}\text { Destaca-se vários fatores impeditivos: o } \\
\text { preconceito, o machismo, a falta de tempo, } \\
\text { crenças, valores culturais e impossibilidade de se } \\
\text { ausentar do trabalho. Cabe ressaltar que estão } \\
\text { associados também à falta de educação } \\
\text { continuada para os profissionais de saúde, e a } \\
\text { falta de estrutura física adequada para atender as } \\
\text { particularidades desta população. }\end{array}$ \\
\hline $\begin{array}{l}\text { Rodrigues et al. } \\
2016\end{array}$ & $\begin{array}{c}\text { Conhecer as percepções de } \\
\text { trabalhadores de duas equipes de } \\
\text { Unidades de Saúde da Família em } \\
\text { relação ao processo de implantação } \\
\text { da PNAISH. }\end{array}$ & $\begin{array}{l}\text { Estudo de } \\
\text { abordagem } \\
\text { qualitativa, } \\
\text { descritivo e } \\
\text { exploratório }\end{array}$ & $\begin{array}{l}\text { Qualitativo/ } \\
\text { Nível } 5\end{array}$ & $\begin{array}{l}\text { A implantação da PNAISH tem se configurado } \\
\text { um importante desafio para os profissionais } \\
\text { sujeitos deste estudo, pois vários entrevistados } \\
\text { desconhece o leque de ações que podem ser } \\
\text { implementadas para sua efetivação assim como } \\
\text { percebem como não satisfatórias as práticas } \\
\text { implementadas em sua unidade. Destacam-se as } \\
\text { escassas ações com vistas a atender as } \\
\text { necessidades da população masculina. Estas } \\
\text { poucas ações centram-se na perspectiva } \\
\text { curativista baseada no modelo biomédico. }\end{array}$ \\
\hline Silva et al. 2016 & $\begin{array}{l}\text { Conhecer as percepções de homens } \\
\text { sobre as suas necessidades em } \\
\text { saúde e se elas são atendidas pelos } \\
\text { serviços de atenção primária de } \\
\text { saúde do município de Cuiabá-MT. }\end{array}$ & $\begin{array}{l}\text { Estudo exploratório } \\
\text { com entrevista } \\
\text { semiestruturada }\end{array}$ & $\begin{array}{l}\text { Qualitativo/ } \\
\text { Nível } 5\end{array}$ & $\begin{array}{l}\text { Os entrevistados concebem como principal } \\
\text { necessidade em saúde o trabalho, como fonte de } \\
\text { provimento financeiro, e que a necessidade de } \\
\text { ser bem acolhido e ter vínculo com o profissional } \\
\text { que o atende não são atendidas nas unidades } \\
\text { primárias de saúde, devido à falta de qualificação } \\
\text { profissional para lidar com esse público. }\end{array}$ \\
\hline $\begin{array}{l}\text { De Almeida et al. } \\
2018\end{array}$ & $\begin{array}{l}\text { Identificar na ótica do usuário } \\
\text { fatores que dificultam a adesão do } \\
\text { homem aos serviços de saúde } \\
\text { disponibilizados nas ações de } \\
\text { promoção e prevenção. }\end{array}$ & $\begin{array}{l}\text { Estudo } \\
\text { quantitativo, } \\
\text { transversal, } \\
\text { descritivo }\end{array}$ & $\begin{array}{l}\text { Qualitativo/ } \\
\text { Nível } 5\end{array}$ & $\begin{array}{l}\text { Destes } 86 \% \text { não procuram os serviços } \\
\text { disponibilizados pela atenção básica, } 77 \% \\
\text { apontaram não ter adoecido não necessitando } \\
\text { assim de nenhum serviço de saúde, declaram ser } \\
\text { uma população saudável e apontam que não } \\
\text { procuram pelos serviços de saúde pela posição de } \\
\text { provedor, muitos alegam que o horário do }\end{array}$ \\
\hline
\end{tabular}




\begin{tabular}{|c|c|c|c|c|}
\hline & & & & $\begin{array}{l}\text { funcionamento dos serviços de saúde coincide } \\
\text { com o horário do trabalho. }\end{array}$ \\
\hline $\begin{array}{l}\text { Ramos, A. B. F. } \\
2019\end{array}$ & $\begin{array}{l}\text { Descrever as estratégias do } \\
\text { enfermeiro nas Unidades Básicas } \\
\text { de Saúde na inclusão do homem na } \\
\text { promoção e prevenção da saúde. }\end{array}$ & $\begin{array}{l}\text { Estudo descritivo e } \\
\text { explicativo, com } \\
\text { abordagem } \\
\text { qualitativa }\end{array}$ & $\begin{array}{l}\text { Qualitativo/ } \\
\text { Nível } 5\end{array}$ & $\begin{array}{l}\text { Os enfermeiros buscam estratégias através de } \\
\text { rodas de conversas, sala de espera, onde os } \\
\text { encontram como acompanhantes e não para } \\
\text { consultar, inseri-los nos atendimentos, a } \\
\text { participação nas consultas de pré-natal, apesar de } \\
\text { ter essas ações como iniciativas e tentativas, não } \\
\text { há ainda ações totalmente direcionadas ao } \\
\text { homem fora do período "Novembro Azul". A } \\
\text { falta de capacitação dos profissionais acaba } \\
\text { sendo um desafio que impede a elaboração de } \\
\text { ações direcionadas ao público-alvo, além das } \\
\text { dificuldades já existentes, entre elas: a ideia } \\
\text { masculina de apenas procurar os serviços de } \\
\text { saúde quando há uma patologia instalada e que } \\
\text { esteja prejudicando em seu trabalho e os horários } \\
\text { das UBSs coincidirem ao do trabalho do homem. }\end{array}$ \\
\hline $\begin{array}{l}\text { Da Rocha et al. } \\
2019\end{array}$ & $\begin{array}{l}\text { Demonstrar a importância de } \\
\text { discutir a necessidade da disciplina } \\
\text { de saúde do homem no curso de } \\
\text { enfermagem }\end{array}$ & $\begin{array}{l}\text { Relato de } \\
\text { experiência }\end{array}$ & $\begin{array}{l}\text { Qualitativo/ } \\
\text { Nível } 5\end{array}$ & $\begin{array}{c}\text { Identificou que a construção social da } \\
\text { masculinidade é um dos grandes fatores que } \\
\text { impedem a população masculina na busca pelo } \\
\text { serviço de Atenção Primária à Saúde (APS). } \\
\text { Destaca-se que as unidades de saúde não estão } \\
\text { estruturadas e preparadas adequadamente para o } \\
\text { atendimento masculino na sua integralidade. } \\
\text { Identificou que é imprescindível a inclusão de } \\
\text { conteúdos sobre homens e masculinidades na } \\
\text { grade dos cursos da área da saúde, a fim de } \\
\text { propiciar um melhor atendimento dentro das } \\
\text { diretrizes da saúde do homem. } \\
\end{array}$ \\
\hline
\end{tabular}

Fonte: Autoria própria.

Nesse sentido, a partir da análise dos dados, emergiram três categorias temáticas, quais sejam: 1. Dificuldade para implantação e implementação; 2. O homem e os serviços de saúde; 3. Atuação dos profissionais de saúde na implementação da política de saúde do homem.

\section{Discussão}

\section{Categoria 1. Dificuldade para implantação e implementação}

Uma política específica para homens configura uma inovação, visto que os homens não foram historicamente, sujeitos singularizados nas intervenções desenvolvidas no âmbito brasileiro em relação à saúde (Leal et al., 2012).

A necessidade de implantação de uma política de saúde voltada para o homem é relevante, pois sua figura influenciada pela sociedade impossibilitou o acesso aos serviços de saúde. Desse modo, acredita-se que esse grupo, desconheça as práticas de saúde e os serviços ofertados na atenção primária, além de não se perceberem como sujeitos inseridos dentro dos espaços de saúde.

Mozer e Côrrea (2014) demonstram que a literatura científica exibe as necessidades em saúde masculina que não se limitam aos males da próstata e outras enfermidades relativas aos aspectos biológicos, dessa forma é preciso considerar os aspectos psicossociais e culturais, sem restringir o cuidado às ações assistenciais ou de caráter emergencial.

A PNAISH foi organizada em conjunto com a Política Nacional de Atenção Básica (PNAB) e com base em consensos construídos a partir de uma discussão que envolveu, além do próprio MS, organizações da sociedade (associações médicas e movimentos sociais organizados), pesquisadores, universitários e representantes de conselhos de saúde, buscando apoio em fortalecer as ações e serviços em redes de cuidado com ações de saúde que contribuam significativamente para a compreensão da realidade singular masculina (Oliveira et al., 2015).

A designação de uma equipe ou de um responsável por uma área nova, a da Saúde do Homem, é apontada como um requisito fundamental para a implementação da PNAISH. Assim, Leal et al. (2015) pontuaram em seu estudo a ausência de 
uma gerência específica no nível municipal, como um desafio, que atue como referência para a promoção de ações voltadas para a saúde do homem.

Esse aspecto condiz com a definição de um estudo feito por Mozer e Corrêa (2014), que desde a instituição da PNAISH, ocorreram inúmeras mudanças na gestão política e administrativa dos municípios selecionados para implantação da mesma, gerando a descontinuidade das ações propostas, uma vez que a cada novo gestor que assume a função de Secretário Municipal de Saúde, novas propostas são encaminhadas, novas equipes técnicas são constituídas e novas prioridades em saúde estabelecidas, determinando a variação do manejo da gestão nos diversos níveis de atenção à saúde, fato que interfere no processo de implementação da PNAISH.

A dificuldade na implantação do programa de saúde a atenção do homem é evidente em muitos municípios, sendo as regiões mais distantes dos grandes centros as mais afetadas. Rocha et al. (2016) enfatizam que as dificuldades para implantação e implementação da PNAISH, está associada na falta de infraestrutura organizacional e sistematização dos serviços de atenção primária à saúde, para atender a população masculina.

Diante dos aspectos abordados anteriormente, nota-se que não houve um mapeamento da realidade onde a política seria implementada, implicando no desconhecimento de serviços, entidades e organizações, públicas ou da sociedade civil, que poderiam atuar em parceria com o setor saúde. Em razão disso, a implantação e implementação da PNAISH vem acontecendo lentamente no território nacional, e sua consolidação percorre por problemas estruturais, administrativos e políticos.

\section{Categoria 2. O homem e os serviços de saúde}

O comportamento social do homem é reflexo do modelo hegemônico de masculinidade, no qual é considerada normal a desvalorização do autocuidado, e como consequência, tem-se a baixa participação desses indivíduos nos espaços de Atenção Primária à Saúde (Silva et al., 2016).

Desta forma, é preciso reconhecer que a não adesão masculina aos serviços de saúde tem como base, os estereótipos de gênero baseados em características culturais, dentre elas, o conceito de que a busca pela assistência de saúde fragiliza a posição do ser homem na sociedade.

Ao tentar entender os motivos da falta de demanda pelos serviços de saúde masculina, De Almeida et al. (2018) em seu estudo descobriram que os problemas com a imagem do homem no imaginário cultural, são questões influenciadoras, como o medo de descobrir que está doente e a vergonha de expor seu corpo. Outro problema está relacionado ao mercado de trabalho, pois a falta de garantia de que o acesso e a frequência dos homens aos serviços de saúde não prejudicará seu trabalho. Além disso, as campanhas públicas de saúde e os serviços de saúde não são condizentes com esse grupo, sendo quase impossível resolver as necessidades dos homens.

Para os homens, as atividades laborais são particularmente importantes, principalmente entre aqueles de baixa condição social, pois a sua história deve ser atribuída aos responsáveis pelo sustento familiar.

A pesquisa realizada por Rodrigues et al. (2016) mostrou que a maioria dos homens procuram pela unidade de saúde para consultas médicas, e declararam frequentar a unidade básica unicamente para realização de exames de rotina. Quanto à procura da assistência médica na hora do adoecimento, os entrevistados declararam que buscaram atendimento na unidade básica de saúde, em hospital particular, na Unidade de Pronto Atendimento (UPA) 24 horas ou em hospital regional.

A baixa procura das práticas preventivas pela população masculina é notória, ela só existe na presença de dor ou enfermidade instalada que esteja prejudicando o desempenho no trabalho, dessa forma, percebe-se ainda, a grande valorização pelas consultas curativas e ignoram-se as ações de caráter preventivo (Teixeira et al., 2014). 
Silva e Magalhães (2015) certificam que se os homens procurassem as unidades de saúde da família de forma mais continua, talvez evitasse o agravamento de futuras patologias e também evitando a morte de alguns que já chegam às unidades com doenças no estágio final, além de reduzir custos financeiros e cansaço físicos mental da família e amigos.

Essa percepção induz homens a buscarem por serviços de maior complexidade, ocasionando a sobrecarga nesses espaços, com necessidades que poderiam ser solucionadas na Atenção Básica (Silva et al., 2016).

O estudo feito por De Almeida et al. (2018) confirma nosso achado destacando que os fatores institucionais, tais como dinâmicas dos serviços de saúde e seus horários de funcionamento, que por vezes, chocam com o mesmo horário de demais atividades laborais dos homens, como seu oficio ocupacional.

Os desafios quando se relaciona a ações voltadas aos homens, são significativos, uma vez que o cuidado e a valorização do corpo são vistos como algo irrelevante e infere na demonstração de sinais de fraqueza, impotência, medo e insegurança, indo a sentido oposto ao modelo de masculinidade: viril, forte, invulnerável (Rocha et al., 2016).

Assim, a principal pergunta é: qual o modo de sensibilizar os homens para que cuidem de si e busquem uma unidade de saúde da APS para prevenção de agravos e promoção à saúde? Essa sensibilização começa pela identificação das características sociais, econômicas e culturais dos homens que receberão a atenção à saúde, assim é importante sua participação no planejamento das ações a serem desenvolvidas, de modo que possam realmente ser sujeitos ativos de todo o processo, com responsabilidades definidas (Ferreira, 2013).

\section{Categoria 3. Atuação dos profissionais de saúde na implementação da política de saúde do homem.}

As ações de educação, promoção e prevenção de agravos à saúde em relação a população masculina e a PNAISH devem ser realizadas pelo profissional de saúde na atenção básica, de forma a esclarecer dúvidas e estimular o cuidado com a própria saúde.

Adamy et al. (2015) concluíram que para a implantação da PNAISH, os gestores do SUS no âmbito municipal devem conhecer a proposta, e este é responsável por sua implantação, desenvolvimento e regulação, pautados nos princípios do SUS. Os gestores e a equipe técnica em saúde devem discutir a saúde do homem e a incluir ações e estratégias nas prioridades do município, estabelecendo metas e disponibilizando recursos financeiros para a execução desta política.

Contudo, o processo organizacional em volta dessa política não permite aos profissionais, inseridos na assistência primária, estarem aptos a realizar ações e alcançar os objetivos propostos por eixos inseridos na política, em consequência da ausência de capacitação e instrumentos metodológicos que atinjam esses profissionais e os qualifiquem para o atendimento ao homem.

O MS compôs na efetivação da PNAISH que a educação permanente para o profissional é indispensável na realização de qualquer atividade de saúde. Os profissionais necessitam de preparo para lidar com mitos, preconceitos e concepções errôneas que foram construídas no imaginário e no contexto social dos usuários (Brasil, 2009). Mas para isso, é preciso que a qualificação continuada seja intensificada no cotidiano das ações de gestão e assistência aos serviços e saúde.

Isso foi descrito no estudo de Araújo et al. (2014) que as dificuldades indicadas pelos profissionais estão vinculadas à falta de habilidades e práticas para lidar com a população masculina, devido a lacuna existente nos serviços de saúde e as estratégias de aproximação com o homem e ainda, a capacitação e qualificação profissional é algo necessário e pode ser uma das soluções para minimizar as barreiras predominantes no atendimento ao homem, além de permitir a realização de abordagens as quais privilegiem a população masculina de forma integral e não apenas a doença.

Deste modo, os profissionais reconhecem a necessidade de trabalhar com a população masculina, sendo preciso incentivo e fortalecimento de práticas que facilitem a realização de ações para a inserção do homem nos serviços de saúde. 
De acordo com Silva e Magalhães (2015) a baixa procura da população masculina as unidades básica de saúde impede a criação de novas estratégias para a captura desses homens uma vez que não se sabe ao certo quais são suas reais necessidades, desse modo impedindo as medidas de promover os cuidados na população masculina.

Portando, as dificuldades de acesso da população masculina perpassam pelos profissionais e suas necessidades de ação, pois estes na sua maioria não desenvolvem ações voltadas para o homem, que os aproximem dos serviços de saúde. A disponibilidade de instrumentos para capacitar esses profissionais é imprescindível, além da organização de implementação fortalece os mecanismos de inserção dos profissionais na comunidade e favorece o conhecimento e as singularidades pertencentes ao contexto social predominante de cada indivíduo.

Este trabalho teve como limitação a escassez de estudos sobre a PNAISH no Estado, bem como, analisar a evolução das ações realizadas na atenção básica.

\section{Considerações Finais}

A implantação da PNAISH foi um marco importante no que se refere à assistência à saúde da população masculina no Brasil. No entanto, é percebe-se que diversas condições estão associadas à dificuldade na implementação da mesma no país.

Para a consolidação da política é fundamental superar barreiras políticas, socioeconômicas e culturais, visto que constata desafios para a implantação da PNAISH, de modo a reforçar essa política tão importante à população masculina.

É imprescindível ter profissionais qualificados no atendimento específico desse público, a falta de educação continuada e a falta de estrutura física adequada para atender as particularidades desta população, dificultam a implementação de ações voltadas a PNAISH.

Este trabalho é uma contribuição científica para que os gestores e profissionais de saúde percebam as barreiras que envolvem a prática da assistência à saúde do homem e construam estratégias para sensibilizar essa população da necessidade do cuidado, sugere-se que os trabalhos de pesquisa em saúde do homem, futuramente, devam caracterizar sobre o acesso dos homens aos serviços de saúde e o não acesso, levando em consideração o modelo do homem atualmente na sociedade.

Ao final ressalta-se que a capacitação dos profissionais de saúde pode ter início na graduação, onde os profissionais iniciam suas carreiras cientes da deficiência que precisa ser suprida no sistema, e assim promover o vínculo entre paciente e serviço de saúde, aumentando a qualidade de vida dos homens. E que, a organização de atividades assistenciais de promoção da saúde e prevenção de doenças, nas empresas, nas residências, em locais onde o homem está inserido com mais frequência na sociedade, como bares, estádios de futebol e igrejas, além da adequação quanto o horário de funcionamento nas unidades, tornam-se fundamental para a sensibilização deste grupo.

\section{Referências}

Adamy, E. K., de Lima Trindade, L., Teixeira, D. C., Brambilla, D. K., \& Galli, K. B. (2015). Política nacional de atenção integral a saúde do homem: visão dos gestores do SUS. Revista de Pesquisa Cuidado é Fundamental Online, 7(2), 2415-2424.

Araújo, M. G. D., Lima, G. A. F. D., Holanda, C. S. M. D., Carvalho, J. B. L. D., \& Sales, L. K. O. (2014). Professional opinion on the effectiveness of the National Policy of Comprehensive Health Care for Men. Escola Anna Nery, 18, 682-689.

Brasil. Ministério da Saúde (2009). Secretaria de Atenção à Saúde, Departamento de Ações Programáticas Estratégicas. Política Nacional de Atenção Integral à Saúde do Homem, Plano de Ação Nacional 2009-2011. Brasília.

Da Rocha, E. M., Medeiros, A. D. L., Rodrigues, K. S. L. F., Cruz, J. P. M., Siqueira, M. F. C., Farias, E. F. N., \& Lemes, A. G. (2016). A política nacional de saúde do homem e os desafios de sua implementação na atenção primária à saúde. Revista Eletrônica Interdisciplinar, 1(15).

Da Rocha, E. M., Vilela, A. C., Rodrigues, A. A, Santos, M. V. C., \& Lemes, A. G. (2019) Ressignificando a saúde do homem com a extensão universitária. Revista Panorâmica online Edição Especial - Projetos de Extensão UFMT/CUA.

De Almeida, A. M., Bernardi, A., Gomes, R., de Almeida, T. P., \& dos Santos Oliveira, K. (2018). Assistência à saúde do homem na atenção básica: dificuldades evidenciadas pelos usuários. TCC-Enfermagem. 
Research, Society and Development, v. 11, n. 2, e5311225354, 2022

(CC BY 4.0) | ISSN 2525-3409 | DOI: http://dx.doi.org/10.33448/rsd-v11i2.25354

De Sousa, L. M. M., Marques-Vieira, C. M. A., Severino, S. S. P., \& Antunes, A. V. (2017). A metodologia de revisão integrativa da literatura em enfermagem. No21 Série 2-Novembro 2017, 17.

Duarte, S. J. H., de Oliveira, J. R., \& de Souza, R. R. (2012). A Política Saúde do Homem e sua operacionalização na Atenção Primária à Saúde. Revista Eletrônica Gestão e Saúde, (1), 308-317.

Ferreira, M. C. (2013). Desafios da política de atenção à saúde do homem: análise das barreiras enfrentadas para sua consolidação. SER Social, 4(1), 15551569 .

Garcia, J. T, Cabral M. C. A, Arruda C. do R. A, Santos L. T, Barbosa H. A. (2013). O homem e a saúde: uma revisão integrativa da literatura. EFDeportes.com, Revista Digital, Ano 18, $\mathrm{n}^{\circ} 184$.

Leal, A. F., Figueiredo, W. D. S., \& Nogueira-da-Silva, G. S. (2012). O percurso da Política Nacional de Atenção Integral à Saúde dos Homens (PNAISH), desde a sua formulação até sua implementação nos serviços públicos locais de atenção à saúde. Ciência \& Saúde Coletiva, 17, 2607-2616.

Lopes, C. S. (2015). Promoção da saúde do homem: assistência de enfermagem nas estratégias da saúde da família (ESFs) no município de Cáceres-MT [monografia]. Cáceres(MT): Universidade do Estado de Mato Grosso.

Mozer, I. T., \& Corrêa, Á. C. D. P. (2014). Implementation of the National Policy for Men's Health: case in a Brazilian capital. Escola Anna Nery, 18, 578585 .

Oliveira, M. M. D., Daher, D. V., Silva, J. L. L. D., \& Andrade, S. S. C. D. A. (2015). Men's health in question: seeking assistance in primary health care. Ciência \& saúde coletiva, 20, 273-278.

Ramos, A. B. F. (2019). Saúde do homem: o papel do enfermeiro na unidade básica de saúde Mato Grosso.

[monografia]. Cáceres(MT): Universidade do Estado de

Rodrigues, T. C., Correa, Á. C. P., de Oliveira, J. C. A. X., \& Fraga, L. (2016). Percepção das equipes de saúde da família sobre a implantação da política saúde do homem. Revista Eletrônica Gestão e Saúde, (1), 906-925.

Silva, L. A., de Paula Corrêa, Á. C., Oliveira, J. C. A. X., Rodrigues, T. C., \& do Amor Divino, E. (2016). < b> Percepções de homens trabalhadores sobre suas necessidades de saúde em um serviço universitário de saúde/Men's workers perceptions about their health needs in a university health service< b. Ciência, Cuidado e Saúde, 15(1), 133-140.

Silva, R. L., \& Magalhães, J. (2015). Percepção do cenário atual da saúde do homem: dificuldades encontradas por indivíduos masculinos em monitoramento contínuo de pressão arterial e diabetes na procura por assistência de saúde em Cáceres-MT. Revista Ciência e Estudos Acadêmicos de Medicina, 1(03).

Stetler, C. B., Morsi, D., Rucki, S., Broughton, S., Corrigan, B., Fitzgerald, J., \& Sheridan, E. A. (1998). Utilization-focused integrative reviews in a nursing service. Applied Nursing Research, 11(4), 195-206.

Teixeira, R. C., Mandú, E. N. T., Corrêa, Á. C. D. P., \& Marcon, S. S. (2014). Vivências e necessidades de saúde de homens no período pós-nascimento de um filho. Revista Brasileira de Enfermagem, 67, 780-787. 